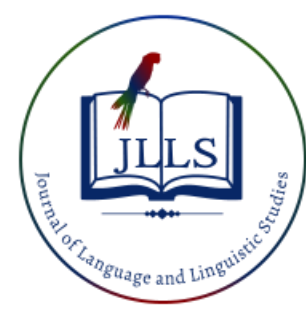

Available online at www.jlls.org

JOURNAL OF LANGUAGE

AND LINGUISTIC STUDIES

ISSN: $1305-578 \mathrm{X}$

Journal of Language and Linguistic Studies, 17(4), 2174-2188; 2021

\title{
A Bibliometric review of research on oral traditions: An overview of over 100
}

\author{
years of studies
}

\author{
Hasliza Abd Halim a1 iD, Aidi Ahmi $^{\text {b iD }}$, Mohd Hilmi Hamzah ${ }^{\text {c }}$ iD, Ahmad Mohammad Yaseen \\ Shorman d iD, Nor Kalsum Mohd Isa e ID
${ }^{a, c}$ School of Languages, Civilisation and Philosophy, Universiti Utara Malaysia.
${ }^{b}$ Tunku Puteri Intan Safinaz. School of Accountancy, Universiti Utara Malaysia
${ }^{d}$ Awang Had Salleh Graduate School, Universiti Utara Malaysia \\ ${ }^{e}$ Faculty of Human Sciences, Universiti Pendidikan Sultan Idris, Malaysia
}

\section{APA Citation:}

Halim, H.A., Ahmi, A., Hamzah, M.H., Shorman, A.M.Y., \& Isa, N.K.M. (2021). A Bibliometric review of research on oral traditions: An overview of over 100 years of studies. Journal of Language and Linguistic Studies, 17(4), 2174-2188. Doi: 10.52462/jlls.158

Submission Date:26/05/2021

Acceptance Date:16/08/2021

\begin{abstract}
Oral tradition refers to the dissemination of cultural materials through oral or oral discourse. Elements like history, literature, and other cultural heritage are transmitted across generations. However, limited scholarly attention has been devoted to mapping the overview of this research area. Thus, this study addresses the shortcoming by mapping the current trend of the study on oral tradition. The data extracted from Scopus database has been analysed using bibliometric analysis. The search using keywords related to oral tradition has extracted about 486 documents over 100 years for publication analysis. The research productivity is reported together along with document and source type, language, country/region, active institution publishing, author, subject area, keyword and publication distribution of citation analysis. The data of 132 years has shown an increament of development rate of literature on the oral tradition from 1888 until 2020. The results show that various studies have been conducted in this research area related to the collaboration of multi-authors. The published articles are using several different languages however the published documents are mostly written in the English language. Among other languages used for publications, i.e., Spanish, French, and Turkish. Our findings provide significant input on the trend of oral traditions research across the globe.
\end{abstract}

Keywords: oral tradition; bibliometric analysis; Scopus database; publication analysis

\section{Introduction}

Oral tradition is generally known for every society to spread literature, history, rules, norms and other knowledge across generations. Oral traditions are basically divided into two categories; verbal and non-verbal. According to Heissig and Schott (1998), oral traditions like legends, faitytales, myths, epic songs, proverbs, riddles and other various genres are considered as each community's heritage and should be treasured. Both oral and written traditions play important roles for each ethnic to be preserved and conveyed from one generation to the next.

\footnotetext{
${ }^{1}$ Corresponding author:

E-mail address: haslieza@uum.edu.my
} 
Most of the survival skills such as making weapons, hunting, fishing, building a fire, putting up shelters or houses, or even rituals, were taught by telling and showing one another how to do these things. Apart from those basic skills, social activities like singing, telling stories, and local dramas and plays are also means of passing knowledge through oral tradition. Kral and Renganathan (2017) define oral tradition as a rich word that points to the process by which individuals connect the past and the present while building the future. It is seen as a symbolic process that both presume past symbolisms and reinterprets them in a very creative way. Thus, oral traditions are perceived as a unique heritage with special nature. However, the powers of memory is definitely the key to preserve the oral traditions. The preservation may lead to the survival of the tradition to shared and spread to the next generations of human beings.

Oral traditions reflect how native speakers put the linguistic resources that they have at their disposal. One of the main resources for oral formulation performance is the oral formulation list. The formulas are obviously lexicalised language fragments, just like ordinary phonetic idioms (Kuiper, 1991). Schmitt (2005) has highlighted that the extensive amount of formulaic language has allowed for the possibility of proficient speaker to become fluent speakers. What is more, formulas act as the agent for speakers in dealing with real-time language production and comprehension while at the same time maintaining fluency (Coulmas, 1981; Kuiper, 2004; Kuiper et al., 2017). The work of Lord and Parry has shown how Yugoslavian illiterate oral bards composed their poems in real-time yet at the same time the fluency is maintained. The composition was made spontaneous yet the live performance was not interrupted at all.

Kuiper (1991) highlights that the most significant contribution to oral traditions has been made by Milman Parry and Albert Lord $(1960,1986)$. Their works have pioneered in this research area. John Miles Foley $(1988,1990,1995)$ is another leading voice in the study of oral literature. The studies are highlighting the South Slavic epic traditions.

Finnegan (2003) studies oral traditions and verbal arts from many aspects. Finnegan provides guidelines for approaching the study of oral form and performances. The African oral literature has been extensively investigated and documented as it is believed that such creative works of oral literature are increasingly endangered due to globalisation and other challenges (Finnegan, 2012).

A vanishing oral culture in the Asian context, named Tekná is a an oral tradition among the Kayan community. Roselind Wan, Reganathan, and Kral (2018) believed that documenting this oral tradition of non-literate indigenous communities is an important step in preserving the survival of indigenous culture, knowledge and tradition. The study has emphasised that this unique Sarawak culture is treated beyond a song performance. Tekná performance manifested the identity of Kayan as well as expressing their uniqueness.

Researchers have extensively explored oral tradition studies over the last century and have found them to be conducted and documented from different continents and countries all over the world. It has proven how oral traditions reflect the beautiful nature of each culture and the local community. In order to retain its visibility, an in-depth analysis should be applied in visualising the trend of research carried out related to oral tradition. Kuiper (1991) states the roots of the contemporary study of oral tradition lie in the German Romantic movement, and yet the trend of research hasn't been traced and mapped systematically. The mapping of this contemporary study of oral culture would embark on eliciting an interesting point of oral tradition research. This publication analysis of over a century is an attempt to develop an extensive and comprehensive review of oral tradition studies.

With the aid of bibliometric analysis, the study aims to investigate the trend of literature published in the field of oral traditions. This study is expected to map an overview of the trend of oral tradition research across the globe for over 100 years. 


\section{Literature Review}

There have been relatively limited studies in reporting the trends and mapping the literature of oral tradition research using bibliometric approach. Despite growing interest in applying this method for various research areas, oral traditions studies require a quantitative analysis of written publication which this approach can offer. There are various terms associated with bibliometric such as informetric, webometrics and also scientometrics ((Egghe and Rousseau, 1990; Wolfram, 2003; Bar-Ilan 2008, 2010). All these methods might somehow similar in nature and help to analyse the dataset in reliable ways.

There are evidences proving how bibliometric analysis treats both quantitative data and qualitative aspects of the research evaluation. Various variant can be interpreted like h-index or any similar values like publishing in high impact journals (Herther, 2009; Hirsch, 2005). Apart from that, bibliometric methods are also used to rank research departments and institutions.

Thus, the current study aims to identify the trends and latest development associated with oral traditions and providing insights for future research directions. The data and analysis presented in this study is identifying and listing the patterns of publications using a bibliometric analysis.

\section{Methodology}

This paper focuses on evaluating current trends and the latest development of academic literature on oral traditions by using the bibliometric analysis method. Bibliometric research is defined as a method that utilises a specific statistical technique to analyse published documents (Zhang, Chen, Wang, and Ordóñez de Pablos, 2016). Bibliometric analysis has gained attention among researchers in highlighting research trends in specific areas (Ahmi and Mohammad, 2019).

The bibliometric analysis gives insights into focused research areas by revealing related facts and details of publications on a specific issue or area. The detailed information could extract specific data such as authors, publication type, h-index, location of publication, keywords, and citations (Ahmi and Mohd Nasir, 2019). The analysis is driven by the VOSviewer. It is a tool which is well designed in creating and visualing the connected associations of networks. VOSviewer also produces a visualisation of network co-occurrence based on the terms extracted from the literature review. Using VOSviewer, this study also further investigates the impact of publications based on citation counts, impact per publication, and citation per publication. Harzing's Publish or Perish was another tool used to extract the citation metrics and related analysis.While Microsoft Excel generated the data and ran frequency analysis.

The analysis is made possible by utilizing the data available in the Scopus database. The search has extracted the data from the year 1888 until 2020. The relevant keywords, such as oral tradition, or oral traditions, have been used for the search. Based on these terms, this study manages to obtain 486 related documents over 100 years. Those keywords were the only focus for the title search because they represent the relevant topic within the scope of the oral tradition theory. It is believed that the title of an article would reflect the content as well as creating interest among potential readers.

\section{Findings and Results}

In order to get an overview of oral tradition research, the overall figures and details related to oral traditions publications are introduced. There are traits and categorical aspects considered to be analysed which are: research trends, document and source type, publication language, subject area, active source title, country/region publication status, most active institution, author, keywords, and citation analyses. Most of the findings are presented as the frequency in the form of percentages. The VOSviewer was 
used to report the co-occurrences of the authors and co-authorship, countries authorship, and keywords analysis.

\section{Research Productivity}

The number of document published yearly is traced and analysed. The year of publication illustrates the trend of the research theme and focus over time (Ahmi and Mohammad, 2019). From the data obtained, it is known that the first publication on oral traditions was published by Miller and Chomsky in the year 1888. Since then, the growth of publication has increased until 2020. As shown in Table 1 and Figure 1, this number has increased yearly, and the number of publications related to oral traditions was the highest in 2018 represents 37 number of publications. To the present time, the publication activity on oral traditions had been increasing from the year 2000. Table 1 provides detailed information on oral tradition publications since 1888. According to the model of the number of oral traditions, it seems that the topic of oral traditions is a favourite topic among academia, and the trend is slowly increasing.

Table 1. Total number of publications by year

\begin{tabular}{|c|c|c|c|}
\hline Year & Total Publication (TP) & Percentage (\%) & Cumulative Percentage (\%) \\
\hline 1888 & 1 & 0.21 & 0.21 \\
\hline 1896 & 1 & 0.21 & 0.41 \\
\hline 1915 & 1 & 0.21 & 0.62 \\
\hline 1950 & 2 & 0.41 & 1.03 \\
\hline 1961 & 1 & 0.21 & 1.23 \\
\hline 1963 & 2 & 0.41 & 1.65 \\
\hline 1964 & 1 & 0.21 & 1.85 \\
\hline 1965 & 1 & 0.21 & 2.06 \\
\hline 1966 & 1 & 0.21 & 2.26 \\
\hline 1967 & 3 & 0.62 & 2.88 \\
\hline 1968 & 5 & 1.03 & 3.91 \\
\hline 1969 & 3 & 0.62 & 4.53 \\
\hline 1970 & 3 & 0.62 & 5.14 \\
\hline 1971 & 2 & 0.41 & 5.56 \\
\hline 1972 & 2 & 0.41 & 5.97 \\
\hline 1973 & 4 & 0.82 & 6.79 \\
\hline 1974 & 3 & 0.62 & 7.41 \\
\hline 1975 & 2 & 0.41 & 7.82 \\
\hline 1976 & 2 & 0.41 & 8.23 \\
\hline 1977 & 1 & 0.21 & 8.44 \\
\hline 1979 & 4 & 0.82 & 9.26 \\
\hline 1980 & 4 & 0.82 & 10.08 \\
\hline 1981 & 4 & 0.82 & 10.91 \\
\hline 1982 & 1 & 0.21 & 11.11 \\
\hline 1983 & 4 & 0.82 & 11.93 \\
\hline 1984 & 2 & 0.41 & 12.35 \\
\hline 1985 & 7 & 1.44 & 13.79 \\
\hline 1986 & 7 & 1.44 & 15.23 \\
\hline 1988 & 3 & 0.62 & 15.84 \\
\hline 1989 & 8 & 1.65 & 17.49 \\
\hline 1990 & 6 & 1.23 & 18.72 \\
\hline 1991 & 4 & 0.82 & 19.55 \\
\hline 1992 & 5 & 1.03 & 20.58 \\
\hline 1994 & 4 & 0.82 & 21.40 \\
\hline 1995 & 6 & 1.23 & 22.63 \\
\hline 1996 & 4 & 0.82 & 23.46 \\
\hline 1997 & 4 & 0.82 & 24.28 \\
\hline 1998 & 4 & 0.82 & 25.10 \\
\hline
\end{tabular}




\begin{tabular}{cccc}
\hline Year & Total Publication (TP) & Percentage (\%) & Cumulative Percentage (\%) \\
\hline 1999 & 5 & 1.03 & 26.13 \\
2000 & 6 & 1.23 & 27.37 \\
2001 & 5 & 1.03 & 28.40 \\
2002 & 13 & 2.67 & 31.07 \\
2003 & 10 & 2.06 & 33.13 \\
2004 & 15 & 3.09 & 36.21 \\
2005 & 11 & 2.26 & 38.48 \\
2006 & 17 & 3.50 & 41.98 \\
2007 & 17 & 3.50 & 45.47 \\
2008 & 18 & 3.70 & 49.18 \\
2009 & 21 & 4.32 & 53.50 \\
2010 & 16 & 3.29 & 56.79 \\
2011 & 22 & 4.53 & 61.32 \\
2012 & 16 & 3.29 & 64.61 \\
2013 & 15 & 3.09 & 67.70 \\
2014 & 20 & 4.12 & 71.81 \\
2015 & 15 & 3.09 & 78.90 \\
2016 & 19 & 3.91 & 86.21 \\
2017 & 36 & 7.41 & 93.83 \\
2018 & 37 & 7.61 & 97.74 \\
2019 & 19 & 3.91 & \\
2020 & 11 & 2.26 & \\
\hline Total & $\mathbf{4 8 6}$ & $\mathbf{1 0 0 . 0 0}$ & \\
\hline
\end{tabular}

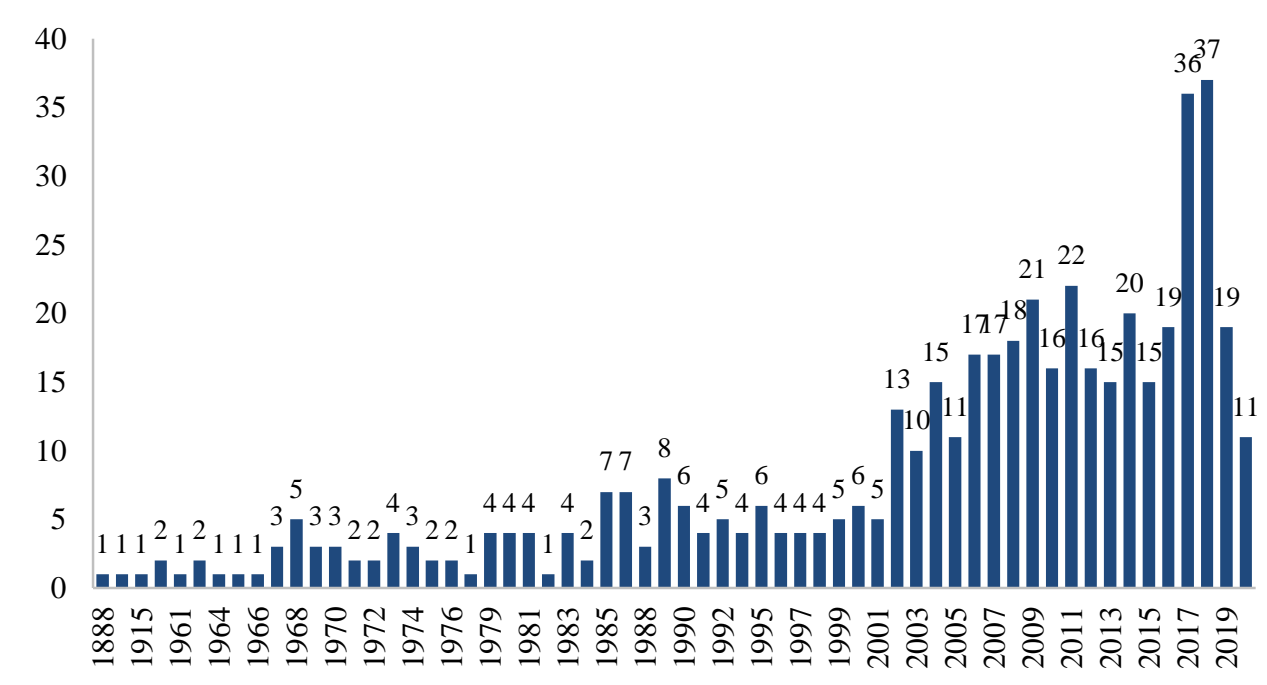

Figure 1. The trend of publications by year

\section{Document and Source Type}

The dataset is further analysed according to the types of document and source. The document type refers to the documents which are dealing with the documents' origin or source. Journal articles, and conference proceedings, are among the examples. While source type refers to documents categorised as the type of the source documents where it deals with the the nature of the document (Sweileh et al., 2017). The extracted data has illustrated that there are ten types of published documents on oral traditions studies, including journal articles, review, conference papers, book chapters, editorial, notes, book, and short survey as shown in Table 2 and Figure 2. 
Table 2. Document type

\begin{tabular}{lcc}
$\begin{array}{l}\text { Document } \\
\text { Type }\end{array}$ & Total Publications (TP) & $\begin{array}{c}\text { Percentage } \\
(\boldsymbol{\%})\end{array}$ \\
\hline Article & 305 & 62.76 \\
\hline Book Chapter & 71 & 14.61 \\
\hline Review & 68 & 13.99 \\
\hline Book & 22 & 4.53 \\
\hline Conference & 7 & 1.44 \\
Paper & & \\
\hline Letter & 4 & 0.82 \\
\hline Editorial & 3 & 0.62 \\
\hline Note & 3 & 0.62 \\
\hline Erratum & 2 & 0.41 \\
\hline Short Survey & 1 & 0.21 \\
\hline Total & $\mathbf{4 8 6}$ & $\mathbf{1 0 0 . 0 0}$ \\
\hline
\end{tabular}

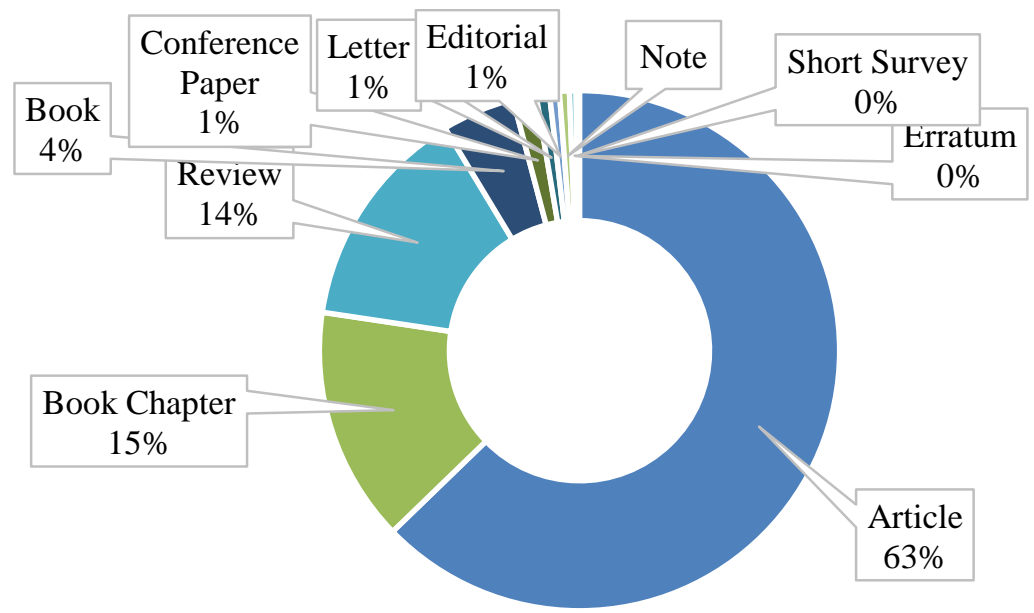

Figure 2. Document by types

At the same time, as shown in Table 3, there are different categories of documents listed under source types. Journals are the highest type of sources, with a total of 373 documents $(76.75 \%)$, followed by the book with 88 documents representing $18.11 \%$ of the total publications and conference proceedings with five documents.

Table 3. Source type

\begin{tabular}{lcc}
\hline Source Type & $\begin{array}{c}\text { Total Publications } \\
\text { (TP) }\end{array}$ & $\begin{array}{c}\text { Percentage } \\
(\boldsymbol{\%})\end{array}$ \\
\hline Journal & 373 & 76.75 \\
Book & 88 & 18.11 \\
Book Series & 17 & 3.50 \\
Conference Proceeding & 5 & 1.03 \\
Trade Journal & 3 & 0.62 \\
\hline Total & $\mathbf{4 8 6}$ & $\mathbf{1 0 0 . 0 0}$ \\
\hline
\end{tabular}




\section{Languages of Documents}

The gathered data sets were also analysed to determine the language used in the published documents. Table 4 below shows the language used for publications on oral traditions. English is found as the main medium used for to publish work related to oral traditionbs $(90.33 \%)$. The percentage for other languages like Turkish, German, French, and Spanish, as shown in Table 4. Some of the published documents were prepared in dual languages.

Table 4. Languages used for publication

\begin{tabular}{lcc}
\hline Language & $\begin{array}{c}\text { Total Publications } \\
(\mathbf{T P}) *\end{array}$ & $\begin{array}{c}\text { Percentage } \\
(\boldsymbol{\%})\end{array}$ \\
\hline English & 439 & 86.25 \\
\hline Spanish & 29 & 5.70 \\
\hline French & 14 & 2.75 \\
\hline Turkish & 10 & 1.96 \\
\hline German & 4 & 0.79 \\
\hline Russian & 3 & 0.59 \\
\hline Slovenian & 3 & 0.59 \\
\hline Croatian & 2 & 0.39 \\
\hline Italian & 2 & 0.39 \\
\hline Portuguese & 2 & 0.39 \\
\hline Czech & 1 & 0.20 \\
\hline Total & $\mathbf{5 0 9}$ & $\mathbf{1 0 0 . 0 0}$ \\
\hline \multicolumn{2}{c}{ *Dual languages documents. }
\end{tabular}

\section{Subject Area}

Next, the publications based on the subject area presented in Table 5. As studies on oral traditions are related to art and culture, it is found that more than $71.60 \%$ of the total were categorised under Arts and Humanities. This is followed by Social Sciences (66.26\%). Both Arts and Humanities, as well as Social Sciences have dominated the subject areas. Among other subject areas ; Environmental Science, Engineering, Computer Science, Medicine, Earth and Planetary Sciences, Psychology, and Agricultural, as shown in Table 5.

Table 5. Subject area

\begin{tabular}{lcc}
\hline Subject Area & $\begin{array}{c}\text { Total Publications } \\
\text { (TP) }\end{array}$ & $\begin{array}{c}\text { Percentage } \\
(\mathbf{\%})\end{array}$ \\
\hline Arts and Humanities & 348 & 71.60 \\
\hline Social Sciences & 322 & 66.26 \\
\hline Earth and Planetary Sciences & 24 & 4.94 \\
\hline Environmental Science & 20 & 4.12 \\
\hline Medicine & 12 & 2.47 \\
\hline Computer Science & 9 & 1.85 \\
\hline Psychology & 9 & 1.85 \\
\hline Agricultural and Biological Sciences & 8 & 1.65 \\
\hline Engineering & 6 & 1.23 \\
\hline Nursing & 5 & 1.03 \\
\hline Dentistry & 3 & 0.62 \\
\hline Mathematics & 3 & 0.62 \\
\hline Economics, Econometrics and Finance & 2 & 0.41 \\
\hline Energy & 2 & 0.41 \\
\hline Multidisciplinary & 2 & 0.41 \\
\hline Business, Management and Accounting & 1 & 0.21 \\
\hline Health Professions & 1 & 0.21 \\
\hline
\end{tabular}




\begin{tabular}{lcc}
\hline Subject Area & $\begin{array}{c}\text { Total Publications } \\
\text { (TP) }\end{array}$ & $\begin{array}{c}\text { Percentage } \\
(\boldsymbol{\%})\end{array}$ \\
\hline Physics and Astronomy & 1 & 0.21 \\
\hline
\end{tabular}

\section{Geographical Distribution of Publications}

The dataset has illustrated the most active countries that published articles in the area of oral traditions. What is found is that the three most active countries are United States, United Kingdom and Canada. Other countries listed with less than 30 publications are Spain, France, Australia, Germany and New Zealand. From the statistics, it is found that only two Asian countries listed in the top 20 countries publishing the research documents in this area of study. Indonesia and India contributed 5 and 7 publications, respectively.

Table 6. Top 20 countries contributed to the publications

\begin{tabular}{lc}
\hline Country & $\begin{array}{c}\text { Total Publications } \\
\text { (TP) }\end{array}$ \\
\hline United States & 131 \\
\hline United Kingdom & 39 \\
\hline Canada & 31 \\
\hline Spain & 22 \\
\hline France & 15 \\
\hline Australia & 10 \\
\hline Germany & 10 \\
\hline New Zealand & 10 \\
\hline South Africa & 10 \\
\hline Turkey & 9 \\
\hline India & 7 \\
\hline Netherlands & 6 \\
\hline Indonesia & 5 \\
\hline Israel & 5 \\
\hline Italy & 5 \\
\hline Russian Federation & 5 \\
\hline Brazil & 4 \\
\hline Hungary & 4 \\
\hline Nigeria & 4 \\
\hline Slovenia & 4 \\
\hline
\end{tabular}

\section{Publication by Institution}

The number of publication by the institutions is also another aspect to measure productivity of research done in oral traditions. Table 7 shows that Massey University Manawatu has published more than 5 publications on oral traditions. The University of Glasgow, University of Waikato, University of Missouri, Harvard University, The University of Arizona, University of Oregon, and the University of Aberdeen become the second highest followed by The Ohio State University, University of Auckland, The University of British Columbia, and the University of Alberta, as shown in Table 7. 
Table 7. Number of publications by institutions (with a minimum of two publications)

\begin{tabular}{|c|c|c|}
\hline Institution & No. of Publications & $\begin{array}{c}\text { Percentage } \\
(\%)\end{array}$ \\
\hline Massey University Manawatu & 7 & 1.44 \\
\hline University of Glasgow & 5 & 1.03 \\
\hline University of Waikato & 5 & 1.03 \\
\hline University of Missouri & 5 & 1.03 \\
\hline Harvard University & 5 & 1.03 \\
\hline The University of Arizona & 5 & 1.03 \\
\hline University of Oregon & 5 & 1.03 \\
\hline University of Aberdeen & 5 & 1.03 \\
\hline The Ohio State University & 4 & 0.82 \\
\hline University of Auckland & 4 & 0.82 \\
\hline The University of British Columbia & 4 & 0.82 \\
\hline University of Alberta & 4 & 0.82 \\
\hline $\begin{array}{l}\text { University of Illinois at Urbana- } \\
\text { Champaign }\end{array}$ & 3 & 0.62 \\
\hline Western Michigan University & 3 & 0.62 \\
\hline Közép-Európai Egyetem & 3 & 0.62 \\
\hline American Museum of Natural History & 3 & 0.62 \\
\hline Brandeis University & 3 & 0.62 \\
\hline University of Toronto & 3 & 0.62 \\
\hline University of Otago & 3 & 0.62 \\
\hline Manaaki Whenua - Landcare Research & 3 & 0.62 \\
\hline Monash University & 3 & 0.62 \\
\hline Leiden University & 3 & 0.62 \\
\hline Durham University & 3 & 0.62 \\
\hline University of California, Berkeley & 3 & 0.62 \\
\hline The University of Edinburgh & 3 & 0.62 \\
\hline Kubin Community Council & 2 & 0.41 \\
\hline Rhodes College & 2 & 0.41 \\
\hline University of Cape Town & 2 & 0.41 \\
\hline University of Calgary & 2 & 0.41 \\
\hline Prifysgol Abertawe & 2 & 0.41 \\
\hline University of KwaZulu-Natal & 2 & 0.41 \\
\hline Stanford University & 2 & 0.41 \\
\hline Imo State University & 2 & 0.41 \\
\hline Balikesir Üniversitesi & 2 & 0.41 \\
\hline Universidad de Jaen & 2 & 0.41 \\
\hline University of Saskatchewan & 2 & 0.41 \\
\hline University of Washington, Seattle & 2 & 0.41 \\
\hline Universidad de Cadiz & 2 & 0.41 \\
\hline US National Park Service & 2 & 0.41 \\
\hline University of Ghana & 2 & 0.41 \\
\hline
\end{tabular}

\section{Authorship analysis}

The extracted data has revealed the number of authors who frequently published the literature on oral traditions. A minimum of three publications per author is recorded. Based on Table 8, Roa, T., Whaanga, H., Foley, J.M., Spät, E., and Wehi, P.M are identified as most frequent authors publishing research documents in the field of oral traditions, as shown in Table 8. Tom Roa and Hemi Whaanga have the highest number of publications, followed by John Miles Foley, Eszter Spat, and Pricilla M Wehi. 
Table 8. 10 Most active authors

\begin{tabular}{lcc}
\hline Author Name & No. of Publications & Percentage (\%) \\
\hline Roa, T. & 5 & 1.03 \\
\hline Whaanga, H. & 5 & 1.03 \\
\hline Foley, J.M. & 4 & 0.82 \\
\hline Spät, E. & 3 & 0.62 \\
\hline Wehi, P.M. & 3 & 0.62 \\
\hline Aragāo, P. & 2 & 0.41 \\
\hline Atkinson, D. & 2 & 0.41 \\
\hline Bernardini, W. & 2 & 0.41 \\
\hline Bloch, L. & 2 & 0.41 \\
\hline Carroll, L. J. & 2 & 0.41 \\
\hline
\end{tabular}

This section further analyses the co-authorship among the countries. The collaborations between authors are shown in Figure 3. The network visualisation map of the authors based on the countries they are affiliated with is presented to show the relationship. We choose all countries that publish at least one publication. According to the complete counting method, the findings indicate that the United States, the United Kingdom, and Canada are dominating the role in the research collaborations. There are two clusters of collaboration among countries. Cluster 1 (see Figure 3), which is coloured as red, is a group of countries that normally collaborate among the authors affiliated to those particular countries, while cluster 2 is coloured as green.

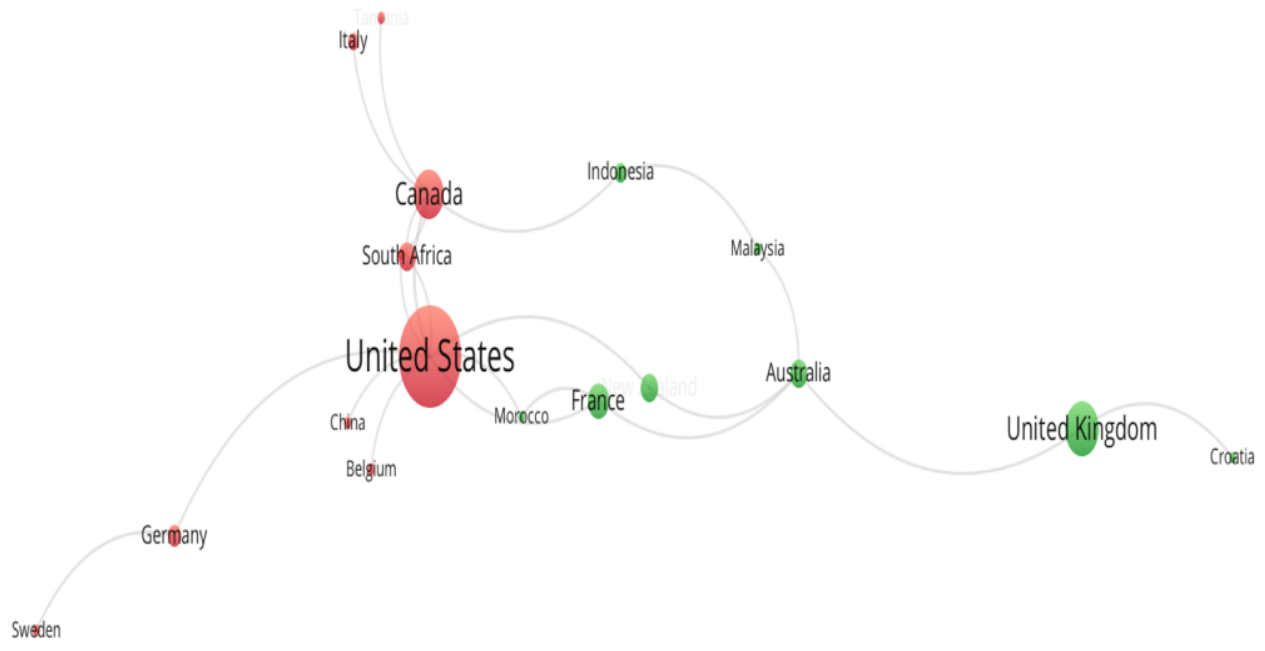

Figure 3. Network visualisation map of the authors from different countries

\section{Keywords Analysis}

The author keyword has also been counted as essential elements to reflect the associated issues in oral tradition studies. The VOSviewer as presented in Figure 4 shows the web visualisation of author keywords. It should be noted that features like font size, colour, circle size, and connecting line thickness are among the indicators to show the keywords' relationship. The analysis has established five clusters in association with oral traditions research. The cluster coloured in blue, is related to performance, oral tradition, oral traditions, oral history, oral literature, and storytelling. The red marked cluster is associated with the keywords of history, human, female, and literature, as shown in Figure 4. 


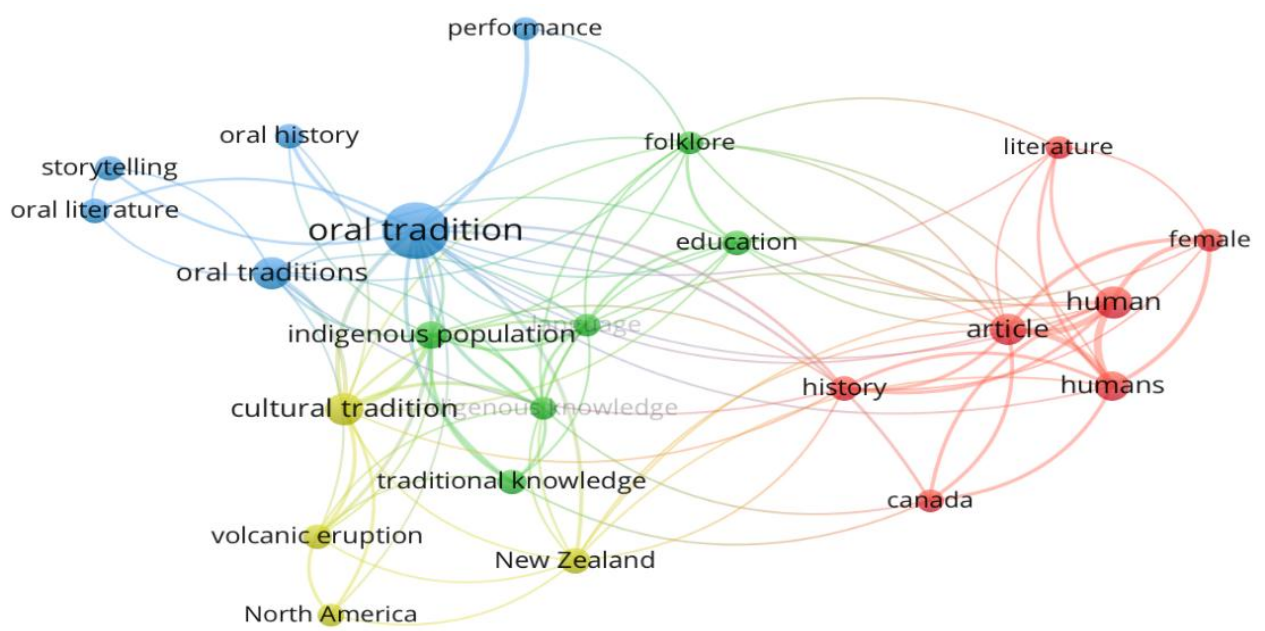

Figure 4. Network visualisation map of the author keywords

\section{Citation Analysis}

The number of citations and citations per year is another aspect to measure the productivity of researchers. Table 9 illustrates the citation metrics for the retrieved documents as of $9^{\text {th }}$ September 2020. The total citations of 2773 has been generated within 132 years (1888-2020) for oral traditions publications. Harzing's Publish and Perish (2010) software has generated the citation metric by importing RIS format files from the Scopus database into the software to display the original citation metric, as shown in Table 9.

Table 9. Citations metrics

\begin{tabular}{ll}
\hline Metrics & Data \\
\hline Total number of papers & 486 \\
\hline Total citations & 2773 \\
\hline Years & 132 \\
\hline Citations/ year & 21.01 \\
\hline Citations / paper & 5.71 \\
\hline Citations / author & 2527 \\
\hline Papers / author & 435.12 \\
\hline Authors / paper & 1.33 \\
\hline h-index value & 24 \\
\hline g-index value & 40 \\
\hline
\end{tabular}

The top 20 most cited articles in oral traditions presented in Table 10 below. The document entitled written by R.C. Echo-Hawk published in the year 2000 is considered as the most impactful article with the 151 citations or an average of 7.55 citations per year.

Table 10. Highly cited articles

\begin{tabular}{llccc}
\hline Authors & Title & Year & TC & C/Y \\
\hline Echo-Hawk & $\begin{array}{l}\text { Ancient history in the New World: Integrating oral traditions } \\
\text { and the archaeological record in deep time }\end{array}$ & 2000 & 151 & 7.55 \\
& Glaciers and climate change: Perspectives from oral tradition & 2001 & 134 & 7.05 \\
\hline J. Cruikshank & Hopi oral tradition and the archaeology of identity & 2005 & 116 & 7.73 \\
\hline W. Bernardini & $\begin{array}{l}\text { Talk that talk: Storytelling and analysis rooted in African } \\
\text { American oral tradition }\end{array}$ & 2002 & 97 & 5.39 \\
\hline J. Banks-Wallace & $\begin{array}{l}2003 \\
\text { Oral traditions and the verbal arts: A guide to research } \\
\text { practices }\end{array}$ & 96 & 5.65 \\
\hline Rinnegan & Archaeology and native North American oral traditions & 2000 & 89 & 4.45 \\
\hline R.J. Mason & & & & \\
\hline
\end{tabular}




\begin{tabular}{|c|c|c|c|c|}
\hline P.M. Whiteley & $\begin{array}{l}\text { Archaeology and oral tradition: The scientific importance of } \\
\text { dialogue }\end{array}$ & 2002 & 68 & 3.78 \\
\hline L.D. Minc & $\begin{array}{l}\text { Scarcity and survival: The role of oral tradition in mediating } \\
\text { subsistence crises }\end{array}$ & 1986 & 67 & 1.97 \\
\hline $\begin{array}{l}\text { K.V. Cashman, } \\
\text { S.J. Cronin }\end{array}$ & $\begin{array}{l}\text { Welcoming a monster to the world: Myths, oral tradition, and } \\
\text { modern societal response to volcanic disasters }\end{array}$ & 2008 & 66 & 5.5 \\
\hline E.S. Alexander & $\begin{array}{l}\text { Transmitting Mishnah: The shaping influence of oral } \\
\text { tradition }\end{array}$ & 2006 & 46 & 3.29 \\
\hline H. Scheub & A review of African oral traditions and literature & 1985 & 39 & 1.11 \\
\hline R.H. Lowie & Oral Tradition and History & 1915 & 36 & 0.34 \\
\hline D.R. Woolf & $\begin{array}{l}\text { The "common voice": History, folklore and oral tradition in } \\
\text { early modern England }\end{array}$ & 1988 & 34 & 1.06 \\
\hline P.J. Claus & $\begin{array}{l}\text { Spirit possession and spirit mediumship from the perspective } \\
\text { of Tulu oral traditions }\end{array}$ & 1979 & 34 & 0.83 \\
\hline M. Lauer & $\begin{array}{l}\text { Oral traditions or situated practices? Understanding how } \\
\text { indigenous communities respond to environmental disasters }\end{array}$ & 2012 & 32 & 4 \\
\hline R.J. Mason & $\begin{array}{l}\text { Inconstant companions: Archaeology and north American } \\
\text { Indian oral traditions }\end{array}$ & 2006 & 31 & 2.21 \\
\hline D.A. Swanson & $\begin{array}{l}\text { Hawaiian oral tradition describes } 400 \text { years of volcanic } \\
\text { activity at Kîlauea. }\end{array}$ & 2008 & 30 & 2.5 \\
\hline H. Moisl & Anglo-Saxon royal genealogies and Germanic oral tradition & 1981 & 27 & 0.69 \\
\hline $\begin{array}{l}\text { D.N. King, J.R. } \\
\text { Goff }\end{array}$ & $\begin{array}{l}\text { Benefitting from differences in knowledge, practice and } \\
\text { belief: Māori oral traditions and natural hazards science }\end{array}$ & 2010 & 26 & 2.6 \\
\hline W. Bernardini & Identity as history hopi clans and the curation of oral tradition & 2008 & 26 & 2.17 \\
\hline
\end{tabular}

\section{Conclusion and Recommendations}

This study has reviewed the academically published documents on oral traditions using bibliometric analysis. The Scopus database generated has mapped a trend of research in this area. The search query from the analysis has identified 486 documents published in related area. The overall results indicate there is a slight grow of the quantity of publications on oral traditions since 1888 to the year 2020 . Yearly data on publication has suggested that only in the year 2002 the number of publication recorded has significantly increased. The data demonstrates that the topic on oral traditions has started to become an emerging topic. Since the year 2017 to 2018 the number of publications boosted dramatically where 36 to 37 publications published during those years. Although progress on this topic has improved, it is still open for more research opportunities in the future. It is found that more than $50 \%$ of documents are published in the form of journal articles. The data has suggested that almost $90 \%$ or more publications were written in English and the publications are contributed by 20 or more identified countries. The United States has dominated the collaboration with other related countries. In terms of cooperation, The United Kingdom is mostly associated with France, while South Africa seems to collaborate with Nigeria.

The most frequent keywords associated with oral traditions are performance, oral history, oral traditions, oral literature, and storytelling. The related key points in this area is projected using the VOSviewer. The use of more related keywords can contribute to more comprehensive research results thus illustrate a wider and quality of the research scope and findings. The citation metrics has disclosed how impactful some articles are written on this topic. The search has yield about 132 years of publications (1888-2020). Overall, there are 486 documents published with a total of 2773 citations.

It is known that any analysis is open for imperfection and open for limitations. The same case applied for bibliometric analysis where some limitations are highlighted. First, the results only generate the exact keywords of oral tradition and oral traditions. So, other related keywords might not be supplied 
and included in this analysis. Therefore, it is urged for more works to be performed. Future research may extend to this.

There might be some shortcomings from the analysis performed in generating the data. It is also worth noting that no search is comprehensive and resulting a 100\% perfect and reliable result. Therefore, many factors should be considered in producing a reliable result (Sweileh et al., 2017). Another limitation is the origin of the data source. The present study only employed the data provided and listed in the Scopus database as the sole data set. This is due to the fact that Scopus is one of the most extensive databases indexing all academic works (Sweileh et al., 2017; Ahmi and Mohamad, 2019). However, despite of the robustness of the data made available by Scopus it may not entirely cover all the related sources. In the future, the search query may also include large database like Web of Science and Google Scholar. Despite these limitations, the current paper contributes to the development of knowledge by introducing and mapping the landscape of research trends on oral traditions. This research also expands and supplements previous findings in traditional oral literature through the use of bibliometrics, and provides meaningful insights into previous literature trends.

\section{Acknowledgements}

This work was supported by the Research Fund provided by RACER/1/2019/SSI01/UUM//2 provided by the Ministry of Education of Malaysia.

\section{References}

Ahmi, A., \& Mohamad, R. (2019). Bibliometric Analysis of Global Scientific Literature on Web Accessibility. International Journal of Recent Technology and Engineering, 7(6), 250-258.

Ahmi, A., \& Mohd Nasir, M. H. (2019). Examining the Trend of the Research on eXtensible Business Reporting Language (XBRL): A Bibliometric Review. International Journal of Innovation, Creativity and Change, 5(2), 1145-1167.

Bar-Ilan, J. (2008). Informetrics at the beginning of the 21st century-A review. Journal of Informetrics, $2(1), 1-52$.

Bar-Ilan, J. (2010). Citations to the "Introduction to informetrics" indexed by WOS, Scopus and Google Scholar. Scientometrics, 82(3), 495-506.

Coulmas, F. (1981). Conversational Routine. The Hague: Mouton.

Egghe, L., \& Rousseau, R. (1990). Introduction to informetrics: Quantitative methods in library, documentation and information science. New York: Elsevier Science Publishers.

Finnegan, R. (2003). Oral traditions and the verbal arts: a guide to research practices. Routledge.

Finnegan, R. (2012). Oral literature in Africa. Open Book Publisher.

Foley J. M., (1988). The theory of oral composition: history and methodology. Indiana University Press.

Foley J. M., (1990). Oral formulaic theory: A folklore case-book. Garland.

Foley J. M., (1995). The singer of tales in performance. Indiana University Press.

Harzing, A.-W. (2010). The publish or perish book: Tarma Software Research Melbourne.

Heissig, W., \& Schott, R. (1998). The Present-Day Importance of Oral Traditions-Their reservationon, Publication and Indexing. In Die heutige Bedeutung oraler Traditionen/The Present-Day 
Importance of Oral Traditions (pp. 26-36). VS Verlag für Sozialwissenschaften. https://doi.org/10.1007/978-3-322-83676-2_2

Herther, N. K. (2009). Research evaluation and citation analysis: Key issues and implications. The Electronic Library, 27(3), 361-375.

Hirsch, J. E. (2005). An index to quantify an individual's scientific research output. Proceedings of the National Academy of Sciences of the United States of America, 102(46), 16569-16572.

Kral, I., \& Renganathan, S. (2017). Beyond school: digital cultural practice as a catalyst for language and literacy. In G. Wigglesworth, J. Simpson and J. Vaughan (eds), Language practices of indigenous children and youth: The transition from home to school. (pp. 365-385). London: Palgrave Macmillan.

Kuiper, K. (1991). The evolution of an oral tradition: race-calling in Canterbury, New Zealand, Oral Traditions, 6(1), 19-34.

Kuiper, K. (2004). Formulaic performance in conventionalised varieties of speech. In N. Schmitt (Ed.), Formulaic sequences: acquisition, processing and use (pp. 37-54). Amsterdam: John Benjamins Publishing Company.

Kuiper, K., Bimesl, N., Kempen, G.\& Ogino M. (2017). Initial and non-initial placement of agent constructions in spoken clauses: A corpus-based study of language production under time pressure. Language Sciences, 1-18.

Lord, A. (1960). The Singer Tales. Harvard University Press.

Lord, A. (1986). Perspectives on recent work on the oral tradition formula, Oral Traditions, 1, 467-503.

Roselind Wan, Sumathi Renganathan \& Inge Kral. (2018). Tekná - a vanishing oral tradition among the Kayan people of Sarawak. Malaysian Borneo, Indonesia and the Malay World, 1-17.

Schmitt, N. (2005). Formulaic language: fixed and varied. ELIA 6, 13-39

Sweileh, W. M., Al-Jabi, S. W., AbuTaha, A. S., Sa'ed, H. Z., Anayah, F. M., \& Sawalha, A. F. (2017). Bibliometric analysis of worldwide scientific literature in mobile-health: 2006-2016. BMC medical informatics and decision making, 17(1), 72.

Wolfram, D. (2003). Applied informetrics for information retrieval research. New Direction in Information Management (No. 36). Westport, CT: Greenwood Publishing Group.

Zhang, X., Chen, H., Wang, W., \& Ordóñez de Pablos, P. (2016). What is the role of IT in innovation? A bibliometric analysis of research development in IT innovation. Behaviour \& Information Technology, 35(12), 1130-1143. doi:10.1080/0144929x.2016.1212403

\section{AUTHOR BIODATA}

Hasliza Abd Halim is senior lecturer at the School of Languages, Civilisation and Philosophy, Universiti Utara Malaysia. She obtained her PhD in Linguistics from University of Canterbury, New Zealand. She completed her M.Ed. TESL from Universiti Pendidikan Sultan Idris (UPSI), and secured her degree of English Language and Literature from International Islamic University Malaysia. Her current research projects are Malaysian traditional oral performances, and also the integration and preservation of endangered indigenous language in Malaysia.

Aidi Ahmi currently is an Associate Professor at the Tunku Puteri Intan Safinaz School of Accountancy, Universiti Utara Malaysia (UUM). He obtained his PhD. in Information Systems and Computing from Brunel University London, United Kingdom. He is a member of the Malaysian Institute of Accountants (MIA) and had been recognised as Professional Technologist (Ts.) by Malaysia Board of Technologies (MBOT). He is also a lifetime 
member of the Malaysian Accounting Association (MyAA) and Internet Society (ISOC) Malaysia and actively involved with the Asian Academic Accounting Association (FourA). So far, he has authored and co-authored over 90 peer-reviewed technical publications and successfully supervised eight $\mathrm{PhD}$ scholars. His research area focuses on accounting information systems, auditing, e-commerce, information and communication technology, and information science.

Mohd Hilmi Hamzah is an Associate Professor at the School of Languages, Civilisation and Philosophy, Universiti Utara Malaysia. He received his PhD in Phonetics from the University of Melbourne, Australia in 2014. His research interests include Phonetics and Phonology, Applied Linguistics, and Teaching English as a Second Language.

Ahmad Mohammad Yaseen Shorman was a Graduate Research Assistant and has doctoral degree in Applied Linguistics from the School of Languages, Civilisation and Philosophy, Universiti Utara Malaysia. (Std Phd : He do not have ORCHID no).

Nor Kalsum Mohd Isa is currently an Associate Professor at Department of Geography and Environment, Universiti Pendidikan Sultan Idris, Malaysia. Her areas of interest include green, low carbon and sustainable development, green and low carbon behaviours and innovation in teaching and learning geography. 